\title{
The Research of Vocational Training Performance in Small and Medium Enterprises in China
}

\author{
Guochao Lin \\ Department of Business Administration \\ Fuzhou University of International Studies and Trade \\ Fuzhou, China \\ E-mail: 521138739@qq.com
}

\begin{abstract}
The purpose of the research is to try find out the importance of employee's performance to business growth, particular focusing on the vocational training in SMEs. It is considered that SMEs who keep their autonomy and market power in a business growth competitiveness position, are those with the highest performance in terms of employees. According to the research, it is difficult to find SMEs with a clear strategy of human resource development: most adjustments concerned other aspects, such as products, markets, and organization structure. As the basic and operational element of a firm, maintaining employee's quality is directly related to the SMEs' continuing business growth. Providing vocational training, learning and development can be a continuing policy to facilitate business growth in SMEs.
\end{abstract}

Keywords-vocational training; business growth; employee behavior

\section{INTRODUCTION}

In the past two decades, the business around world was interested in the creative thinking of Small and Medium Enterprises (SMEs) for its new power in business growth. The focus of business interest shifted from the large enterprises to SMEs. The contribution of SMEs to the economy growth became recognised in both developed countries and developing countries. Nowadays, SMEs are not only the economic growth points and power, but also the main source of economic development, innovation and creation of employment. Empirical evidence confirms the decisive role of SMEs for growth and employment: $99.8 \%$ of all enterprises in Europe have less than 250 employees and SMEs employ the majority of the European workforce. In China, there are 100 million registered SMEs in China, accounting the $90 \%$ of the total registered enterprises and $60 \%$ of the Gross Domestic Product (GDP). However, since 2005, the development of SMEs in China decreased and many firms were bankrupted. One of the most important reasons is lacking of development in human resources and vocational training.

Small and Medium sized Enterprises (SMEs) are regarded as the main drivers of a dynamic economic development. However, the specificity and diversity of SMEs impedes a typology and coherent consideration of the role of SMEs in training and employment creation. In the mass of European
Commission' research, researchers found that if SMEs want to successful in the complex business environment, strategies just focusing on products, markets and organization structure are not enough for a firm to maintain a continuing business growth. Human resource development (HRD), which refers to the activation and development of educational training activities in companies, is also play a significant role in SMEs' business development. Self-employed business, as one kind of SMEs, is popular in China in the recent years. However, with the change of labour market and economic restructure in China, self-employed business is short of qualified workforce to continue its operation in the complex economic environment. It is considered that to be a learning firm can be regarded as an effective strategy to build competitiveness advantage in SMEs' long term business growth.

\section{LITERATURE REVIEW}

Leonardo da Vinci (LDV), a programme of the European Commission, projected a research on 'Training processes in small and medium-sized companies' in 1997. The general aim of this project is to analyse the limited access for European SMEs to continuing vocational training (CVT) activities. The research is based on the survey of 75 manufacturing SMEs per each selected region, and a qualitative analysis of the training supplies available to the same enterprises. The research found that it was difficult to build an efficient continuous vocational training system in SMEs and many of them had barriers to training.

In 1998, Targeted socio-economic research (TSER), a programme of the European Commission, had a project on ' DELOS - developing learning organisation models in SME clusters. SME clusters may act as learning organisations. The path followed by 'organisation learning' is complete in the SME cluster circuit, but instead of taking place in a number of enterprises and also involves a number of different bodies. The research tried to identify operative models of competence development and transfer within and between SMEs. Finally, it gave working indications capable of supporting training and occupational policies to promote SMEs in long-term growth.

TSER organised a research project on 'Small business training and competitiveness: Building case studies in different European cultural contexts' in 2000. The objective of 
this research is to identify learning processes that lead to increase competitiveness in small and medium sized enterprises, and to describe how these learning processes are shaped in different European culture contexts. The result of that project stated that those companies who provided related training based on local culture were more competitively than those who were not.

\section{THE EMPLOYMENT PERFORMANCE OF SMES}

In order to achieve the research objectives, appropriate research methods are used to collect information in those three self-employed business in China: Fuzhou Hine Software Co., Ltd., Fuzhou Haoyiyuan Landscaping Co., Ltd. and Fuqing Jingtai Landscaping Co., Ltd..

\section{A. Performance}

The employment performance of SMEs is influenced by a number of variables. It is considered that the characteristics of the firm will influence the employment performance of SMEs a lot. For example, the size and internal organisation structure of the firm, the sector and position in the value added chain, the age of the firm, status and the modality of production would influence the employment behaviour of SMEs, especially in job descriptions.

Many researchers believe that SMEs are regarded as the main source of economic development, innovation and creation of employment. A considerable part of job creation by SMEs is due to reorganisations of large firms that try to refocus their business by down-sizing, outsourcing or subcontracting. However, some enterprises create many new jobs whereas others destroy many, too. For example, the selfemployed business in China, generally, is difficult to create job positions. These firms are usually young with few operating experience. Owing to that, these firms are weak on the recruitment and training needs assessments of SMEs. The owners of the business are always self-controlled, because the firms are too small to create job positions. Moreover, the managers are always to teach the employee themselves to reduce the cost of operation. However, this will destroy the enthusiasm of workers.

In addition, research has proven that those SMEs that keep their autonomy and market power, are those with the highest performance in terms of employment (Trouvé et al., 2000). However, these are rather few ones. North el al. (1994) conclude that it is difficult to find SMEs with a clear strategy of human resource development: most adjustments concerned other aspects, such as products, markets, and organization structure (p. 253). In China, according to the Chinese Statistic Year book, there are 100 million registered SMEs in China, accounting the $90 \%$ of the total registered enterprises and $60 \%$ of the Gross Domestic Product (GDP). However, in recent years of development, SMEs in China face many serious situations in declining speed of development, bad performance or even bankrupt. One of the most important reasons is unqualified employees and lacking of vocational training. Employee is one of the most important resources in companies. It is necessary for Human Resources Department (HRD) to ensure that all the employees are qualified and he or she is the one that the company need. Therefore, training, learning and development of human resources can be a continuing policy to maintain the continuous employee quality improvement as well as facilitate a business growth in SMEs..

\section{B. Training \& Learning}

SMEs do not only play a role in job creation but also in the integration of young people in the labour market, including training and learning. However, SMEs face difficulties in retaining higher skilled workers and also in completing their initial vocational education and training. Concerning the school-based initial training, such as Spain, Italy, Greece, there is a considerable gap between SMEs' needs of specific competences and the more general qualifications produced by formal training system.

The flexibilisation of employment standards and new relations between training and enterprise are the two significant elements for SMEs to train and recruit skilled workers. The liberalisation of employment standards in several countries encouraged small firms to recruit young people in particular and thus support their integration in work. Closer links between work and training have been established in most countries, in particular by alternance or apprenticeship training programme. For example the Youth Training scheme in the UK takes place in the workplace in a limited duration.

However, the initial training in China is quite different from those in Europe. The initial training in China is based on the education system path. The training develops in different stages of education starting from the primary school. When young workers finish the primary education, they can apply for higher education to middle school or apprenticeship. The training stages go step by step to the higher professional level.

In addition, SMEs are confronted with several difficulties regarding training and skill needs. The general rising qualification level of young generations, as well as their changing aspirations towards future work and career, promotes them to continue training in higher and more prestigious programmes and to look for a job in larger enterprise. High-tech SMEs or those working on new emerging fields recruit higher skilled young people, mostly from the external labour market. Moreover, formal training schemes do not yet exist for many of their activities which reinforce the recruitment of higher qualifications and poaching. However, high qualification level of workers does not mean no training providing in SMEs. In China, because of the education system, the primary training in different school can not catch up with the change of working requirements and development needs in SMEs. Most of the young workers in China lack of practice skills in real working situation. Therefore, continuing vocational training is still needed in SMEs business growth. 


\section{DETERMINANTS OF SMES' TRAINING BEHAVIOUR}

There some reasons for SMEs' weak performance on training behaviour. According to the interview data and secondary research on Training and learning for competence: second report on vocational education and training in Europe, the following determinants are found.

\section{A. Obstacles}

Compared with large business, SMEs are lack of infrastructure for training and many of them mistrust in traditional training for the view that training activities have not strong impact on business growth and most of them focus on the management leadership. Secondly, SMEs are concerning training costs and insufficient means. In order to reduce the cost, the existing training activities are usually with inappropriate training methods, missing analyses of qualification needs, lack of pedagogical competences of internal trainers and lack of SME-knowledge of external trainers. On the other hand, internal factors, such as, disinterest or demotivate of workers, limited time horizon for an adequate training policy, difficulty in replacing workers during their training phase and inability to offer internal career and promotion perspectives after further training, also limit vocational training in SMEs. Chen yu said: 'many SMEs managers fear that trained workers may leave the firm.

One of the effective ways to ease the barriers is to enhance cooperation between SMEs and large firms or between SMEs' networks. The exchange study in Fuzhou Haoyiyuan Landscaping Co., Ltd. and Fuqing Jingtai Landscaping Co., Ltd. The two companies have similar business in landscaping and the exchange study can help the two companies understand each other better. One of the employee from the exchange study group said: 'It is a good way to share technique skills on the field work and different ways to complete the current work.' This corporation will reduce the risk of the obstacles in vocational training. As the situation in Fuzhou Hine Software Co., Ltd. is better than the others two. Referred to the interview, the company has a clear policy in employee's training and working ability development. The manager will assess the workers' quality to clear the gap between the requirements of working tasks and the employees' ability. Therefore, the training activities are directly to the shortage of the employee. Based on this policy, workers can learn more and be happy and interested with their work. Chen yu said: 'the corporation with other large companies or SMEs will reduce the barriers in many ways, especially the cost and infrastructure. The vocational policy in my company not just practices as the human development policy, but also the motivation policy.

\section{B. Formal and Non-formal Training}

A puzzling result was brought forward by Baldwin (1998). According to their research, the most successful smaller businesses tend to train fewer workers than less successful SMEs. The authors solve this puzzle through further specification: the more successful SMEs rely on formal training and less undertake own non-formal training. This leads us to the question between formal and non-formal training within SMEs. According to the research data, the training work in Fuzhou Haoyiyuan Landscaping Co., Ltd. and Fuqing Jingtai Landscaping Co., Ltd. are all non-formal training. The frequent practice is to mentoring a new or lower skilled workers by a good performed or experienced colleagues. This non-formal training limited the acquirement of skills and knowledge. These unprofessional sections contain many mistakes followed by empiricism. This is the reason why these two companies have a slow business growth performance in employee training perspective.

\section{Application of New Technologies in Training}

The main objective of pedagogical innovations in training is an improved adaption of continuing training to the needs and capabilities of SMEs, by means of increased utilisation of information and communication technology, distance learning, network, enterprise clubs, territorial plans or sectoral organisations. It is expected that these training forms improve the flexibility of and accessibility to learning and thus may be better suited for SMEs. As a software service company, Fuzhou Hine Software Co., Ltd. has developed a learning software to support his employees' continuing learning. With the internet technology, the company can share variety of sources to expand employee's knowledge, for example the onlin-training programme. In Chen yu's statement: we are the small and medium enterprise who protects the benefits of employees, because they are the profit maker in the company.

\section{SUGGESTIONS}

In order to maintain continuing growth in business and also limit the development risk, priority must be given to the quantitative and qualitative development of vocational training in SMEs, particular for those self-employed business. As part of the small and medium enterprises, the training of skilled workers and employees at lower level in selfemployed business must be developed and restructured.

\section{A. Restructure the Company Structure and Culture.}

For most self-employed business in China are centralised by the owner, therefore, the leadership style is just follow ' Do what I told you'. It will demotivate employment performance. The company's structure and culture should pay more attention to employee needs and wants.

\section{B. Provide its own Primary Training}

The education system in China limited the young labour force's field practice ability. Most of the knowledge learned from schools can not follow the change of the business environment. The primary section training is important to ensure the work tasks to employees.

\section{Provide Continuing Vocational Training Program}

Provide more continuing vocational training program to improve the employee's skills. It is bad for self-employed business to recruit lower-skilled workers and do not offer 
adequate further training, because the unsustainable labour force will damage the sustainable growth in this small business. Vocational training is a way to gain competitiveness advantage and also a way to maintain the current high skilled people. It can be also regarded as a motivation policy.

\section{CONCLUSION}

Considering the determinants of SMEs' training behaviour, cooperating with large firms and between SMEs is a good way to solve the shortage of training sources. Without vocational training, if company keeps changing its workforce all the time, the high labour turnover will increase SMEs' operating cost and decrease the competitiveness. In order to settle the current vocational training problems in SMEs, the most important thing is to designing effective training and learning activities based on the assessments of employee needs and work requirements. For those SMEs who want to keep continuing growth in a long term development should practice a clear human resource development policy in training to support to support continuing growth of employees' ability.

Therefore, designing effective training and learning activities to SMEs' employees should be the core content of SMEs' Human resource Management. This is also the core suggestion to the self-employed business in China. If small business wants to survive in a long-time business environment, policies in vocational training to maintain continuing growth of employees should be implemented.

\section{ACKNOWLEDGMENT}

This is the project supported by the Office for Education Sciences Planning of Fujian Province. The project name is 'The research on the talents training mode of big data marketing innovation and entrepreneurship in the new era of information'. The program code is FBJG20170207.

\section{REFERENCES}

[1] Aventur F., Möbus M., Philippe C., Dallaporta M., (1998). Continuing vocational training in French companies in 1993-Results of a European survey. Document du Céreq, Vol. 133, 167-229.

[2] Baldwin, J. R., (1998). Were small producers the engines of growth in the Canadian manufacturing sector in the 1980s? Small Business Economics, 10, pp.349-364

[3] Eurostat, 1997. Investigation "Continuing professional education in business" - results 1994 (CVTS). Luxembourg: EUR-OP.

[4] North D., Smallbone D., Leigh R., 1994. Employment and labor process changes in manufacturing SMEs during the 1980s, In Atkinson J., Storey D. (Eds.), Employment, the small firm and the labour market, (pp. 206-255.). London: Routledge,

[5] Trouvé P. et al., 2000. The employment and training practices of SMEs. In Descy P., Tessaring M., (Eds.), Examination of research in five EU Member States, (pp.91-232). Luxembourg: Office for Official Publications of the European Communities.

[6] Kesum. (2011). The vocational training problems and recommendations in SMEs in China. [online]. Available from: http://www.kesum.com/zx/jqzxrd/201107/143841.html

[7] Tsinghua University Training of Leadership. (2010). The current status of vocational training in SMEs. [online]. Available from: http://www.thldl.org.cn/news/1001/30297.html 